\title{
Pilfering for survival: how health workers use access to drugs as a
} coping strategy

\author{
Paulo Ferrinho*1,2,3, Maria Carolina Omar' ${ }^{1}$, Maria de Jesus Fernandes ${ }^{1,2}$, \\ Pierre Blaise $^{4}$, Ana Margarida Bugalho ${ }^{1,3}$ and Wim Van Lerberghe ${ }^{1,5}$
}

\begin{abstract}
Address: ${ }^{1}$ Associação para o Desenvolvimento e Cooperação Garcia de Orta, Lisbon, Portugal, ${ }^{2}$ Centro de Malária e Outras Doenças Tropicais, Universidade Nova de Lisboa, Lisbon, Portugal, ${ }^{3}$ Institute of Preventive Medecine, Faculty of Medicine, Universidade de Lisboa, Lisbon, Portugal, ${ }^{4}$ Institute of Tropical Medicine, Antwerp, Belgium and ${ }^{5}$ Department of Health Systems Policy and Operations, World Health Organization, Geneva, Switzerland

Email: Paulo Ferrinho* - pferrinho@sapo.pt; Maria Carolina Omar - carolinaomar@teledata.mz; Maria de Jesus Fernandes - mjf@hotmail.com; Pierre Blaise - pblaise@itg.be; Ana Margarida Bugalho - margaridab@saudexxi.min-saude.pt; Wim Van Lerberghe - vanlerberghew@who.int

* Corresponding author
\end{abstract}

Published: 28 April 2004

Human Resources for Health 2004, 2:4
Received: 12 September 2003

Accepted: 28 April 2004

This article is available from: http://www.human-resources-health.com/content/2/l/4

(C) 2004 Ferrinho et al; licensee BioMed Central Ltd. This is an Open Access article: verbatim copying and redistribution of this article are permitted in all media for any purpose, provided this notice is preserved along with the article's original URL.

\begin{abstract}
Background: Coping strategies have, in some countries, become so prevalent that it has been widely assumed that the very notion of civil services ethos has completely - and possibly irreversibly - disappeared. This paper describes the importance and the nature of pilfering of drugs by health staff in Mozambique and Cape Verde, as perceived by health professionals from these countries. Their opinions provide pointers as to how to tackle these problems.
\end{abstract}

Methods: This study is based on a self-administered questionnaire addressed to a convenience sample of health workers in Mozambique and in Cape Verde.

Results: The study confirms that misuse of access to pharmaceuticals has become a key element in the coping strategies health personnel develop to deal with difficult living conditions. Different professional groups (mis)use their privileged access in different ways, but doctors diversify most. The study identifies the reasons given for misusing access to drugs, shows how the problem is perceived by the health workers, and discusses the implications for finding solutions to the problem.

Our findings reflect, from the health workers themselves, a conflict between their self image of what it means to be an honest civil servant who wants to do a decent job, and the brute facts of life that make them betray that image. The manifest unease that this provokes is an important observation as such.

Conclusion: Our findings suggest that, even in the difficult circumstances observed in many countries, behaviours that depart from traditional civil servant deontology have not been interiorised as a norm. This ambiguity indicates that interventions to mitigate the erosion of proper conduct would be welcome. The time to act is now, before small-scale individual coping grows into large-scale, well-organized crime. 


\section{Background}

Misuse by health personnel of their privileged access to pharmaceuticals is a sensitive issue in the current context of scarce resources, promotion of generics, HIV epidemic and growing demand for health care. Misappropriation is a widespread practice rarely explicitly acknowledged or documented, even in studies that have looked into the coping strategies of health professionals [1-4]. It is common knowledge that the practice is wide-spread $[5,6]$. For example, in the average Ugandan health facility drug leakage - involving facility health workers as well as District Health Teams and Health Unit Management Committees - is as high as $78 \%$, with resale of drugs representing the greatest single source of income for health workers in most units $[7,8]$. In many other developing countries the situation is supposed to be similar if not worse [9]. All this represents a financial loss to the health care system, and affects health outcomes negatively. It also contributes to the growing sense of mistrust and disrespect for the health professions and their institutions.

By its very nature misuse of access to pharmaceuticals is hard to document directly. An alternative is to ask health workers about what occurs in services without inquiring into their own behaviour. Although basically a record of hearsay, such information can shed light on the type of misuse that occurs, and, more importantly, how this is perceived and valued by the personnel. This paper reports on such perceptions of health staff in Mozambique and Cape Verde. It describes their perceptions of the importance, the nature and the justification of pilfering of drugs in these countries. This provides pointers as to how to tackle the problem.

\section{Methods}

The study used a mixed open-ended and closed questions self-administered questionnaire addressed to a convenience sample of individuals working at various levels in the health sector. Eventually 27 individuals filled the questionnaire in Mozambique, and 26 in Cape Verde. They work in a variety of situations. Together they cover a range of situations where health workers and patients interact or where decisions related to pharmaceutical policy are taken.

\section{Population}

In Mozambique 27 individuals ( 11 doctors, three nurses, one pharmacist and 12 orderlies) answered the questionnaire. There were 15 females and 12 males, ranging in age from 27 to 58 years (median 38 years). All worked in the public sector: two in the ministry of health, two in the provincial health administration, one at district level, eight in hospitals and four in health centres. Six doctors had university appointments. Only 13 (six doctors, three nurses and four orderlies) said they also worked in the private for profit sector and one in the private not for profit sector.

In Cape Verde 26 individuals (four doctors, nine nurses, one pharmacist and 12 orderlies) answered the questionnaire. There were 5 females and 21 males, ranging in age from 25 to 54 years (median 35 years). All worked in the public sector: two at district level, 17 at hospital level, one at pharmacy level and two at health centre level. Only six (two doctors, nine nurses and nine orderlies) reported working also in the private for profit sector and 1 doctor in the private not for profit sector. Five (two nurses and three orderlies) worked in rural areas, the others in town.

\section{Results \\ How access to pharmaceuticals boosts health workers' income}

All respondents in both countries claimed personal knowledge of instances of misappropriation of pharmaceuticals by health personnel for personal financial gain. This took various forms - from outright stealing to requesting under-the-counter payments or overcharging.

"The porter was searched by the security people at the gate, and they found several medicines in his handbag",

"In Nyass a health centre worker removed antibiotics from his workplace to send them across the border to Malawi, in exchange for ... shoes, TV sets, video sets, hi-fi sets, etc. He opened his own shop in town on account of his dishonesty",

"The nurse replaced prescribed post-op pethidine with Diclofenac or Aspergic. He sold the pethidine to drug addicts afterwards", "My mother went to a public hospital and the doctor prescribed injectables. At the hospital pharmacy, the pharmacy technician told us that the injections were out of stock and referred us to one nurse in one of the wards. We went there and the nurse sold us the injections for 300.000,00 meticais (approximately US\$ 20)".

At times respondents would report 'less objectionable' practices: "The pharmacy technician overcharged the patients for drugs but kept only the difference for himself". Twenty-one respondents in Mozambique and seven in Cape Verde included promotion of undesirable prescribing patterns by representatives of the pharmaceutical industry among the ways pharmaceuticals are used to generate personal income.

According to the respondents, the range of unorthodox practices related to the handling of drugs in health facilities is widest among doctors and particularly those active in private practice (Table 1 ). Respondents mainly pointed at doctors and pharmacists, less at nurses - except to say 
Table I: Ways in which health personnel misuse their access to pharmaceuticals for personal gain. Frequency with which each type of misuse was reported by 27 Mozambican (M) and 26 Cape Verdean (CV) respondents.

\begin{tabular}{|c|c|c|c|c|}
\hline & By doctors & By pharmacists & By nurses & By orderlies \\
\hline Stealing & $5 \mathrm{M} 6 \mathrm{CV}$ & $24 \mathrm{M} \mathrm{ICV}$ & $19 \mathrm{M} 8 \mathrm{CV}$ & $16 \mathrm{M} 4 \mathrm{CV}$ \\
\hline Prescription of unnecessary drugs & $20 \mathrm{M} 15 \mathrm{CV}$ & $\begin{array}{l}25 \mathrm{M} 6 \mathrm{CV} \text { (during over } \\
\text { the counter consultations) }\end{array}$ & $20 \mathrm{M}, 8 \mathrm{CV}$ & $\begin{array}{l}\text { I7 M, } 4 \mathrm{CV} \text { (during over- } \\
\text { the-counter consultations) }\end{array}$ \\
\hline Unnecessary prescription of injectables & $21 \mathrm{M} 15 \mathrm{CV}$ & $3 \mathrm{M} I \mathrm{I} C V$ & $4 \mathrm{M}, 0 \mathrm{CV}$ & OM, I CV \\
\hline $\begin{array}{l}\text { Prescription of expensive brand names in lieu of } \\
\text { generic drugs, particularly in private practice }\end{array}$ & $24 \mathrm{M} 15 \mathrm{CV}$ & $24 \mathrm{M} I \mathrm{I} C V$ & $\mathrm{I} \mathrm{M}, \mathrm{OCV}$ & OM, OCV \\
\hline $\begin{array}{l}\text { Substituting prescribed brand-name drugs with } \\
\text { generics }\end{array}$ & $4 \mathrm{M} 16 \mathrm{CV}$ & $23 \mathrm{M} I \mathrm{CV}$ & $0 \mathrm{M}, 6 \mathrm{CV}$ & OM, OCV \\
\hline $\begin{array}{l}\text { Under-the-table payments for supplying supposedly } \\
\text { free drugs }\end{array}$ & $24 \mathrm{M} 16 \mathrm{CV}$ & OM, OCV & OM, OCV & OM, OCV \\
\hline Overcharging & $4 \mathrm{M} 2 \mathrm{CV}$ & $24 \mathrm{M} 8 \mathrm{CV}$ & $0 M, 4 C V$ & $0 \mathrm{M}, 2 \mathrm{CV}$ \\
\hline
\end{tabular}

that nurses in private practice or orderlies in private pharmacies overprescribe.

In both countries respondents said they had the impression that the phenomenon was generalised:

"Everyone knows that stealing of medicines and other medical supplies by health personnel is a common practice in our society",

"I think this is happening all the time in our country ... Let me tell you, this type of things has been going on for a long time and it is not going to end all that easily",

"Anyone going to the market or strolling down any street in town, can meet people selling medicines, usually not health workers, selling medicines. Other stuff such as IUD and other drugs find their way straight to private consulting rooms".

Particularly in Mozambique actual theft of drugs is said to be highly organised: "No one ever steals alone. There are always third parties involved. There is also a distribution circuit. This involves cooking the books to eliminate all evidence of stolen goods, bribing those in charge of supervision, reliable sales' outlets (at home, private pharmacies, in private clinics, in Dumbanengs [informal market outlets] etc.). Recently there is even talk of «contracts» between private clinics and public sector health workers to ensure the steady supply certain types of medicines. Medicines may even be carried across the border to neighbouring countries. These circuits may even be under the control of people not associated with the health care sector, but rather with the import/export business".

Nineteen of the Mozambican respondents (eight doctors, one nurse and 10 orderlies) and thirteen in Cape Verde (eight doctors, one nurse and 10 orderlies) had the impression that such incidents were on the increase. Most if not all the stories typically concerned public sector facil- ities, particularly hospitals: "...these stories happen all the time in the hospitals, but no one talks about them because they are afraid."

\section{Explaining and justifying}

A number of respondents were of the opinion that such practices, including theft, can at times be justified. The public sector does not function well and health professionals have to do whatever they can to help patients:

"People who steal medicines do not do it to get rich, but rather as a favour", "... to help a sick neighbour",

"I can tell you what happened between an in-law of mine and a health auxiliary. My in-law went to a consultation, where he was prescribed Brufen and Amoxicillin. But, as it was late, the pharmacy was closed. Therefore this health auxiliary told him that he had a small supply at home and could sell him the necessary medicines",

"They do these things because there are patients that do not go to the hospital because of the long waiting times. They will rather go to these people to avoid wasting their time in the hospitals".

Most respondents however, implicitly or explicitly condemned such practices, while still attempting to explain and/or justify them in various ways. An obvious explanation is that of "serious lack of motivation" and insufficient salaries: "economic reasons, and low salaries ... those are the reasons ... it is a means of surviving"... "the true reasons for these practices are the low salaries paid by the government".

Acknowledgement of the low salaries does not preclude moral condemnation. A considerable number of respondents interpreted these phenomena in moral terms, as a question of individual ethical characteristics: 
"I do think that it is mostly because of dishonesty and irresponsibility,

"... vanity, is often what drives people",

"I do think that it depends of the conscience of each one, even when the salary is very low, those who carry out their work honestly do not do these things",

"In my opinion it just reflects the bad attributes of people",

"Lack of morals and of civic sense".

These are then related to a general breakdown of norms in society that is associated with liberalisation ("the increase over the past five past years ... is due to the liberalisation of the market", "nowadays medicine is seen as a commercial activity") where it is possible to exploit "the ignorance of our people".

Most comments, however, did not focus on the behaviour of individuals as much as on service organisation and its management that provides the opportunity for misappropriation and misuse:

"Lack of effective control",

"Lack of authority",

"Low salary, lack of incentives, lack of control systems, lack of inspections, absence of systems to receive and keep the daily income resulting from drug sales ",

"The lack of organisation of the pharmacies makes it easy to steal",

"Defective organisation and lack of knowledge from the systems' managers makes it easy for the prevaricators".

Combined with "Lack of penalties, disciplinary or legal" this results in "people doing whatever they want because they know they will not be punished". All this takes place in an environment of laissez-faire: "everyone is trying to go on with their lives, therefore no one worries about disciplinary measures or about punishing the prevaricators", with lack of career structure, workload and working conditions as attenuating circumstances.

\section{The consequences}

The impact of these practices on the health care system is seen as negative. They are said to weaken the public sector health sector and damage people's health:

"The impact is always negative, not only for those who carry it out but also for the whole of society. This negative impact is vis- ible in the weakening of the health structure, results in material damage and creates risks for the public's health".

"The impact is negative, because many times we see a patient who tells us that he took some medicine bought at Sucupira market. Therefore, these practices create stock breaks and also they results in lack of response to medicines later prescribed by the doctor as a result of inappropriate doses of the antibiotics taken without a medical prescription".

Respondents also saw consequences that went beyond the immediate health or financial implications, but touch on the symbolic and the political. "Cape Verde is a country where nobody pays for medicines because they have a social meaning. When these are stolen we are damaging the health units". "... systematic stealing of medicines creates a deficit in the public sector that results in serious damage to its already tarnished reputation", and to the reputation of "the different professional groups: paramedics, nurses and porters). "Patients may be believe there are thieves in the hospital", and "the interaction patient-health personnel becomes just a commercial interaction".

\section{What measures are necessary to minimise the negative impact of these practices?}

Besides overall legal measures - "First of all to define what is or it is not legal", "To enforce the law in the health system of Mozambique", "To create conditions to make it possible to denounce these situations"- the solutions proposed fall into four categories.

The first is to improve the management of the health units:

"Implement a rigorous system of control and management",

"Train the managers",

"Improve the management of the system",

"Increase surveillance, supervision ... ",

"Improve management of the pharmaceutical sector, to improve its supervision in order to expedite the detection of problems",

"More controls not only in the public but also over the private sector ...",

"Train people specifically on pharmaceutical management",

"I do think there should exist a stricter control of the sector right on from the central stores to the most peripheral sales outlets and hospital wards", 
"In our hospital in Praia we are computerising the pharmacy and standardising the package system ... ".

The second group of measures proposed is to focus on the conditions of employment and working conditions of the human resources:

"Give appropriate incentives to the personnel ... and improve their working conditions",

"Harmonise salaries with the cost of living",

"Increase the number of trained pharmacists",

"Study measures to reinvest the funds generated by the local pharmacy locally".

Third, respondents feel one should inform the population

"... if people were better informed by the government, through the media, may be then people would become aware that these practices are damaging those carrying them out as well as innocent bystanders."

"Inform the population not to use medicines unless prescribed by people with the competence to prescribe."

Finally respondents feel one should appeal to personal and professional values:

"Meet with the staff to discuss strategies to reduce these practices",

"Do it by giving the example of impeccable honesty",

"Each person must take conscience of the wrongness in these practices".

Basically the bulk of the claims are for better pay, more control and better management, but surprisingly almost nobody talks about "the application of sanctions, real sanctions", or suggest alternative options, other than those currently in place, to better control prescribers.

\section{Discussion}

The social and professional culture within a profession has a major impact on its practice [10-12]. In the health field pressure from local practice styles is known to be particularly relevant in situations where professionals are uncertain about appropriate treatment norms [13]. Peerinfluence can be positive and effective in improving professional practice $[14,15]$. It is likely that peer pressure works in the opposite direction as well, and the shifting of norms with regard to taking advantage of privileged access to pharmaceuticals illustrates this.
Individual coping strategies have, in some countries, become so prevalent that it is widely assumed that the very notion of civil services ethos has completely - and possibly irreversibly - disappeared. The interviews show that this is not the case. Health workers apparently live a conflict between their self-image as honest civil servant wanting to do a decent job, and the brute facts of life that make them betray that aspiration. The manifest unease that this provokes is an important observation as such. It suggests that, even in the difficult circumstances observed in many countries, behaviours that depart from traditional civil servant deontology have not been interiorised as a norm.

This in turn offers perspectives for containing such practices. That is definitely a complex task. First, it requires a clear separation of personal coping strategies from organised crime and institutional misconduct. Second, it requires an understanding of the justification for and rationalisation of this type of behaviour, but seen in the light of the ambiguities revealed by the respondents to this survey. These ambiguities suggest that interventions to mitigate the erosion of proper conduct would be welcome.

It is quite likely that a combination of dealing with the root causes and of a sequential combination of interventions (regulatory enforcement, education and peer influence) could be effective. The latter has been shown to work to control undesirable prescription behaviour by private pharmacies in Hanoi, Viet Nam [16-19]. Professional behaviour can be changed through "peer influence meetings", particularly if the change is seen as building up public reputation and status [17]. This points to the importance, in the absence of effective regulatory mechanisms, of the role of professional societies in ensuring peer-pressure mechanisms to reduce undesirable coping strategies, and illustrates that income topping up is not the principal or only driving force behind the coping strategies health professionals develop. In order to move forward, we need a better understanding of the mechanisms underlying these set of interventions, and the context in which they were or might be successful. None of them alone can be effective indeed and success stories of some categories of interventions relate probably more to the context in which they could emerge than merely their content. As Pawson [20] puts it: "what works for whom in what circumstances" is indeed a key question.

A significant problem with individual coping strategies is the difficulty to assign individual responsibilities in situations where these are endemic. In these circumstances it might be relevant to introduce legislation that makes the head of an organization or department legally responsible for the actions of that body. This would be a way of 
increasing peer pressure and accountability and of signalling the boundaries of what is tolerable [21]. This could then be combined with peer pressure groups to reduce undesirable coping strategies by supporting members to maintain their personal stance as well as by informing the public of their rights. Making public the membership of such a group could be a way of identifying the non-members, an indirect way of increasing pressure [21].

\section{Conclusions}

This study confirms that health workers in Mozambique and Cape Verde do take advantage of their privileged access to pharmaceuticals. The respondents indicate that the phenomenon is widespread. That doctors are best placed to take advantage in a variety of ways is not really surprising. At a time of pressure for the public sector to create partnerships with the private sector, it is ironical to see to what extent "informal partnerships" already exist.

What happens with drugs in situations such as described here is not trivial. Apart from the economic loss to the State and to the patients, the long-term effects for staff morale and morality are far from negligible, as is, perhaps even more importantly, the effect on the public's trust in their health system and its personnel.

\section{Competing interests}

None declared.

\section{Authors' contributions}

All the authors were involved in planning the research protocol, commenting on the results and reviewing the different drafts of the paper. WVLand PFshared the responsibility for overall co-ordination of the work and writing the drafts that were circulated for comments. MCO carried out the field work in Mozambique. MJF carried out the field work in Cape Verde. $\mathrm{MB}$ entered the data into a data base. PF carried out the statistical analysis and the content analysis of the database.

\section{Acknowledgements}

The work for this paper was supported by the INCO-DEV Programme of the European Commission (contract number ICI8CT980347).

\section{References}

I. Adam Y, Gomes A, Cossa A, Naftal A, Conzo S, Coimbra H, Silva B: Estratégias de sobrevivência do pessoal de saúde num hospital público em Maputo. Revista Médica de Moçambique 1997, Suppl I:S62.

2. Backström B, Gomes ADC, Fresta E, Dias F, Gonçalves A, Lerberghe WV, Ferrinho P: The coping strategies of rural doctors in Portuguese speaking African countries [abstract]. Revista Médica de Moçambique 1997, Suppl I:SI3.

3. Ferrinho $P$, Van Lerberghe W, Julien MR, Fresta E, Gomes A, Dias F, Gonçalves A, Backstrom B: How and why public sector doctors engage in private practice in Portuguese-speaking African countries. Health Policy and Planning 1998, I3(3):332-338.

4. Roenen C, Ferrinho P, Van Dormael M, Conceição MC, Van Lerberghe W: How African doctors make ends meet: an exploration. Tropical Medicine and International Health 1997, 2(2): 127-135

5. Kloos H, Getahun B, Tefari A, Tsadik K, Belay S: Buying drugs in Adis Ababa: a quantitative analysis. In The Context of Medicines in Developing Countries Edited by: van der Geest S, Whyte RS. Autrecht, London and Boston: Kluwer Academic Publishers; 1998.

6. Van der Geest S: The efficiency of inefficiency. Medicine distribution in South Cameroon. Soc Sci Med I 982, I 6(24):2। 45-21 53.

7. Asiimwe D, McPake B, Mwesigye F, Ofoumbi M, Ørtenblad L, Streefland $P$, Turinde $A$ : The private sector activities of public-sector health workers in Uganda. In Private Health Providers in Developing Countries. Serving the Public Interest? Edited by: Bennet S, McPake B, Mills A. London and New Jersey: Zed Books; 1993:I40-I57.

8. McPake B, Asiimwe D, Mwesigye F, Ofumbi M, Streefland P, Turinde A: Coping strategies of health workers in Uganda. In Personnel Performance \& Providing Health Care under Adverse Conditions. Individual Coping Strategies. Studies in Health Services Organisation \& Policy Edited by: Ferrinho P, Van Lerberghe W. Antwerp: ITG Press; 2000: 157-I62.

9. Di Tella R, Savedoff WD, Ed: Diagnosis corruption. Fraud in Latin America's Public Hospitals Washington DC: Inter-American Development Bank; 200I.

10. Cederlof $C$, Tomson G: Private pharmacies and the health sector reform in developing countries - professional and commercial highlights. J Social Adm Pharmacy 1995, 3:101-III.

II. Adams $O$, Hicks V: Pay and non-pay incentives, performance and motivation. Paper prepared for the WHO's workshop on a Global Health Workforce Strategy, Annecy, France 2000 [http://www.who.int/ health-services-delivery/human/workforce/index.htm].

12. Segall M: Human development challenges in health care reform. Studies in Health Services Organisation \& Policy 2000, 16:7-17.

13. Tussing $A D$, Wojtowycz MA: The cesarean section decision in New York State, 1986. Economic and noneconomic aspects. Medical Care 1992, 30(6):529-540.

14. Brugha R, Zwi A: Improving the quality of private sector delivery of public health services: challenges and strategies. Health Policy and Planning 1998, 13:107-1 20.

15. Kumaranayake L, Mujinja P, Hongoro C, Mpembeni R: How do countries regulate the health sector? Evidence from Tanzania and Zimbabwe. Health Policy and Planning 2000, 15:357-367.

16. Chuc NT, Larsson M, Do NT, Diwan VK, Tomson GB, Falkenberg T: Improving private pharmacy practice: a multi-intervention experiment in Hanoi, Vietnam. Journal of Clinical Epidemiology 2002, 55( I I): I I 48-II55.

17. Chalker J, Chuc NT, Falkenberg T, Tomson G: Private pharmacies in Hanoi Vietnam: a randomised trial of a 2 year multi-component intervention on knowledge and stated practice regarding ARI, STD and antibiotic/steroid requests. Tropical Medicine and International Health 2002, 7(9):803-8I0.

18. Larsson M, Kronvall G, Chuc NT, Karlsson I, Lager F, Hanh HD, Tomson G, Falkenberg T: Antibiotic medication and bacterial resistance to antibiotic: a survey of children in a Vietnamese community. Tropical Medicine and International Health 2000, 5(10):7II-72I.

19. Chalker J: Improving antibiotic prescribing in Hai Phong province, Vietnam. The "antibiotic dose" indicator. Bulletin of the World Health Organization 200I, 79(4):3।3-320.

20. Pawson R, Tilley N: Realistic evaluation London: Sage Publication; 1997.

21. Ensor T, Duran-Moreno A: Corruption as a challenge to effective regulation in health sector. In Regulating Entrepreneurial Behaviour in European Health Care Systems Edited by: Saltman R, Busse R, Mossialos E. European Observatory Series. Maidenhead: Open University Press; 2002. 